\title{
Indices of free radical activity in the cerebrospinal fluid in motor neuron disease
}

\author{
J D MITCHELL,* M J JACKSON, $\dagger$ B PENTLAND $\ddagger$ \\ From the University of Edinburgh, Department of Medical Neurology,* Northern General Hospital, Edinburgh, \\ University of Liverpool, Department of Medicine, $\dagger$ Royal Liverpool Hospital, Liverpool, Rehabilitation \\ Medicine Unit $\ddagger$ Astley Ainslie Hospital, Edinburgh, UK
}

SUMMARY Indices of free-radical activity and lipid peroxidation were studied in cerebrospinal fluid samples obtained from 11 patients with motor neuron disease and 11 reference subjects. No differences were found between the two groups. The significance of this finding is discussed in relation to current views of the possible pathogenesis of this disease.

A premature ageing theory for the pathogenesis of motor neuron disease was first proposed in $1902^{1}$ and electromyographic studies have since provided some support for this concept. ${ }^{2}$ The presence of reduced RNA levels with a normal DNA content in surviving motor neurons from patients who have died of motor neuron disease ${ }^{34}$ may reflect impairment of normal transcription mechanisms. It has been suggested that this may be the result of defective enzymatic DNA repair mechanisms, ${ }^{5}$ but recent work on mutagen sensitivity has failed to support this attractive hypothesis. ${ }^{67}$

The accumulation of lipofuscin in motor neurons in motor neuron disease is controversial, ${ }^{89}$ but intraneuronal lipofuscin deposits are a feature of many degenerative neurological disorders including neuronal ceroid lipofuscinosis (NCL). It has been suggested that in NCL increased production of hydroxyl radicals results in abnormal lipid peroxidation and that this might be the basis of the reduced antioxidant activity in the cerebrospinal fluid (CSF) which has been reported in NCL. ${ }^{10}$ Antioxidant therapy has been said to influence the course of this disease. ${ }^{11}$ Intracellular free-radical generation could thus provide an alternative explanation for the nucleic acid changes observed in motor neuron disease. ${ }^{12}$

Address for reprint requests: Dr JD Mitchell, Consultant Neurologist, Royal Preston Hospital, PO Box 66. Preston PR2 4HT, UK.

Received 29 January 1986 and in final revised form 31 December 1986.

Accepted 5 January 1987
Manganese is increased in the spinal cord in motor neuron disease. ${ }^{1314}$ This may be deleterious in that manganese is a possible catalyst of free-radical formation or alternatively, this finding may mark the mobilisation of manganese containing superoxide dismutase (MnSOD), an enzyme important in the degradation of free-radicals. The selenoenzyme, glutathione peroxidase (GTPX), is also involved in these mechanisms, and the increased liver and spinal cord selenium levels reported in motor neuron disease ${ }^{14}$ could represent increased hepatic synthesis of this enzyme, with subsequent accumulation in the spinal cord.

We have, therefore, studied indices of free-radical activity and lipid peroxidation in the CSF of patients with motor neuron disease and compared these with a control group.

\section{Patients and methods}

CSF was obtained at lumbar puncture from 11 motor neuron disease patients and 11 control subjects. The ages of the reference group ranged from 21 to 71 years and the patient group from 49 to 74 years. The diagnosis of motor neuron disease was made independently by two or more neurologists after in-patient investigation comprising biochemical, $\mathrm{CSF}$, electrophysiological and radiological studies including contrast examination when indicated.

The ages and diagnoses of the reference group are given in table 1 . The patient group were classified as to whether they had amyotrophic lateral sclerosis (ALS), progressive muscular atrophy (PMA) or progressive bulbar palsy (PBP). This information is presented in table 2 , where the time which had elapsed between the onset of symptoms and CSF sampling is also given. As far as can be ascertained prepara- 
Table 1 Peroxidation products in cerebrospinal fluid (controls)

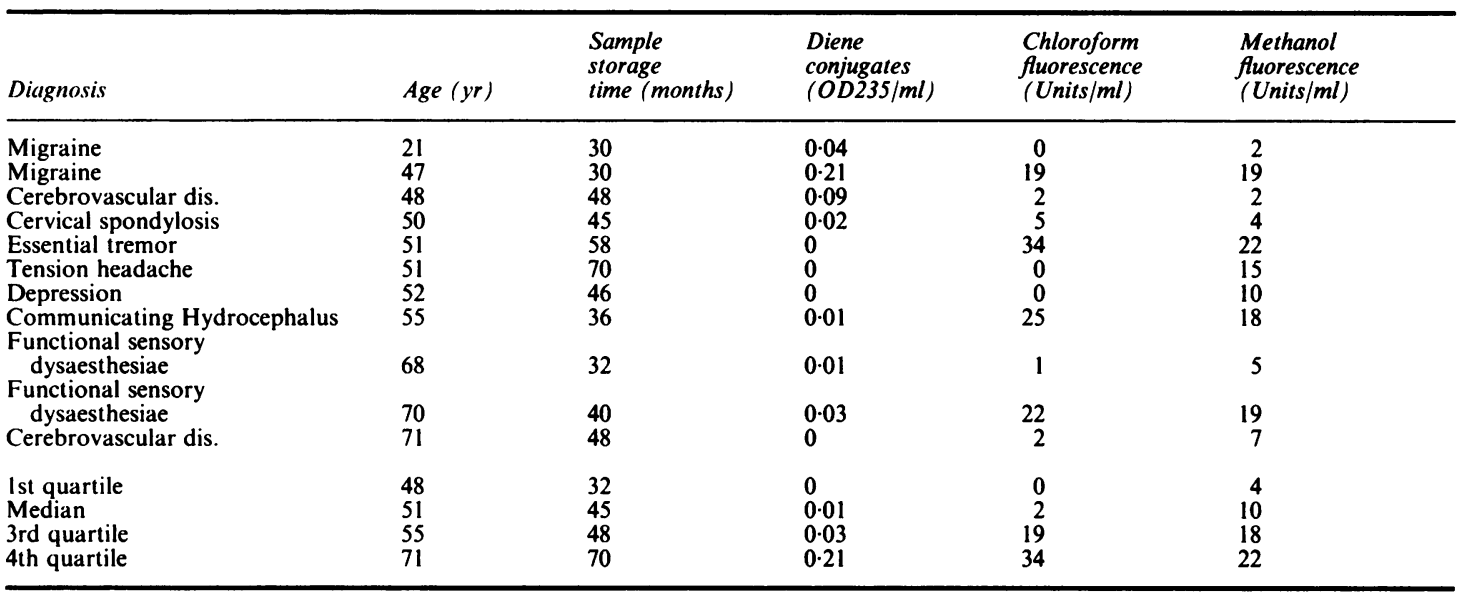

tions containing vitamin $\mathrm{E}$, selenium or non-steroidal antiinflammatory analgesics were not being taken by any of the subjects whose CSF was examined in this work.

The samples were stored in plastic containers at $-20^{\circ} \mathrm{C}$ pending analysis. Three indices of free-radical mediated activities were estimated. Diene conjugates were estimated as a measure of the early stages of lipid peroxidation; chloroform fluorescence as an indicator of free-radical damage to lipids; and methanol fluorescence as an indicator of freeradical mediated damage to membrane proteins. These parameters have been applied widely in free-radical research and are well documented.

In practice CSF samples $(0.5 \mathrm{ml})$ were extracted with chloroform:methanol $(2: 1)$. Water $(2 \mathrm{ml})$ was added and the mix- ture then centrifuged to separate the chloroform and methanol-water layers. Diene conjugates were assessed by measurement of the absorbance at $235 \mathrm{~nm}$ of the chloroform layer against a pure chloroform blank (Cecil CE 594 double beam UV/visible spectrophotometer, Cecil Instruments, Cambridge, England) and the fluorescence of the chloroform layer was measured at excitation and emission wavelengths of $325 \mathrm{~nm}$ and $395 \mathrm{~nm}$ respectively (Perkins-Elmep Model 203 fluorimeter, Perkins-Elmer Ltd, Beaconsfield England). The fluorescence of the methanol-water layer wa: also measured at an excitation wavelength of $360 \mathrm{~nm}$ and an emission wavelength of $460 \mathrm{~nm}$. Wavelength calibration of the fluorimeter was undertaken with quinine sulphate solu? tions, while day to day standardisation was achieved using

Table 2 Peroxidation products in cerebrospinal fluid (patients)

\begin{tabular}{|c|c|c|c|c|c|c|}
\hline Age (yr) & Type & $\begin{array}{l}\text { Duration of } \\
\text { illness at } \\
\text { time of } \\
\text { sampling (months) }\end{array}$ & $\begin{array}{l}\text { Sample } \\
\text { storage } \\
\text { time (months) }\end{array}$ & $\begin{array}{l}\text { Diene } \\
\text { conjugates } \\
(O D 235 / \mathrm{ml})\end{array}$ & $\begin{array}{l}\text { Chloroform } \\
\text { fluorescence } \\
\text { (Units } / \mathrm{ml})\end{array}$ & $\begin{array}{l}\text { Methanol } \\
\text { fluorescence } \\
\text { (Units } / \text { ml) }\end{array}$ \\
\hline $\begin{array}{l}49 \\
56 \\
57 \\
58 \\
60 \\
61 \\
61 \\
62 \\
66 \\
68 \\
74\end{array}$ & $\begin{array}{l}\text { PBP } \\
\text { PMA } \\
\text { PMA } \\
\text { ALS } \\
\text { ALS } \\
\text { PMA } \\
\text { ALS } \\
\text { PBP } \\
\text { PBP } \\
\text { ALS } \\
\text { ALS }\end{array}$ & $\begin{array}{r}3 \\
12 \\
9 \\
48 \\
12 \\
12 \\
12 \\
9 \\
18 \\
32 \\
16\end{array}$ & $\begin{array}{r}40 \\
14 \\
24 \\
5 \\
9 \\
25 \\
42 \\
22 \\
46 \\
24 \\
52\end{array}$ & $\begin{array}{l}0.01 \\
0.05 \\
0.09 \\
0.18 \\
0.08 \\
0 \\
0 \\
0.07 \\
0 \\
0.04 \\
0.05\end{array}$ & $\begin{array}{r}9 \\
7 \\
7 \\
6 \\
10 \\
8 \\
10 \\
13 \\
9 \\
7 \\
11\end{array}$ & $\begin{array}{r}11 \\
5 \\
6 \\
7 \\
12 \\
6 \\
10 \\
7 \\
6 \\
7 \\
4\end{array}$ \\
\hline $\begin{array}{l}57 \\
61 \\
62 \\
74\end{array}$ & $\begin{array}{l}\text { lst } \\
\text { Med } \\
\text { 3rd } \\
4 \text { th }\end{array}$ & $\begin{array}{r}9 \\
12 \\
16 \\
48\end{array}$ & $\begin{array}{l}14 \\
24 \\
40 \\
52\end{array}$ & $\begin{array}{l}0 \\
0.05 \\
0.07 \\
0.18\end{array}$ & $\begin{array}{r}7 \\
9 \\
10 \\
13\end{array}$ & $\begin{array}{r}6 \\
7 \\
7 \\
12\end{array}$ \\
\hline
\end{tabular}

PBP-Progressive bulbar palsy

PMA-Progressive muscular atrophy

ALS-Amyotrophic lateral sclerosis

lst-lst quartile

Med-Median

3rd-3rd quartile

4 th -4 th quartile 
freshly made solutions of reduced nicotinamide adenine dinucleotide (NADH). The coefficient of variation of plasma measurements of each of the parameters considered in this work is estimated to be $<5 \%$. This would be expected to be even less for CSF measurements as the concentrations of protein and other solutes which might interfere with the assay are considerably less in CSF than in plasma. It is felt that the extraction methods used will separate the majority of lipophilic material satisfactorily, the more polar components becoming incorporated in the methanol phase. Although it is a theoretical possibility that other lipid soluble material might absorb at $235 \mathrm{~nm}$ it is considered that this is most unlikely to be of practical importance in the context of this work.

Statistical analysis was undertaken using the method of multiple regression analysis after a modified logarithmic transformation (log [constant + variable]) had been applied to the three indices of free-radical mediated activities. These variables were taken in turn to be the dependent variable with age of patient, duration of sample storage and patient group as the independent variables.

\section{Results}

The absorbance of the chloroform layer at $235 \mathrm{~nm}$ (diene conjugates and the fluorescence of the chloroform and methanol-water layers is given in table 1 for control subjects and in table 2 for the motor neuron disease patients. The duration of sample storage for the two groups is also given in the tables. There was a significant decrease in diene conjugates with increasing length of storage $(p<0.01)$. No such association for either of the other parameters was found even at the $10 \%$ level. No significant differences were found between the two groups with regard to diene conjugates, chloroform fluorescence or methanol fluorescence, either in a univariate analysis or when age and duration of sample storage were allowed for using a multiple regression approach. Nor was there any interaction between patient group and age with respect to any of the indices of free-radical mediated activities.

\section{Discussion}

The data presented here do no not provide any evidence of free-radical mediated damage to lipids or membranes, or of abnormal lipid peroxidation in the CSF in motor neuron disease. Since there is no simple technique which can be used to assess the amount of free-radical mediated damage which occurs in biological systems it is necessary to monitor a variety of different indices. The three parameters which we have examined provide different information on the extent of any free-radical mediated reactions. Diene conjugates are formed at an early stage of the peroxidation of unsaturated fatty acids and have been utilised in the study of lipid peroxidation both in vivo and in vitro. ${ }^{15}$ Fluorescence of lipids (chloroform fluorescence) is on the other hand only found at a late stage of lipid peroxidation and is thought to be due in some part to Schiff bases formed between products of lipid peroxidation such as malonaldehyde and amino acids. ${ }^{16}$ The fluorescence obtained in the methanolwater layer is felt to be derived from free-radical mediated damage to proteins. ${ }^{1718}$ The possibility that other substances might absorb at $235 \mathrm{~nm}$ and thus interfere with the measurements has already been discussed and considered unlikely to be an important consideration. This possibility would seem even less likely in the light of the clear absence of any significant differences between the control and patient groups.

The selection of reference material is difficult in any work involving CSF examination. Obtaining samples from healthy subjects is difficult to justify on ethical grounds. It will be seen that two of the reference subjects had cerebrovascular disease and a third cervical spondylosis. Free-radical mechanisms have been implicated in the mediation of ischaemic tissue damage. An ischaemic basis has also been postulated for some of the myelopathic features seen in cervical spondylosis. None of these three subjects however showed results conspicuously different from the other reference subjects. It is a matter of some controversy whether "free-radical reactions" in cerebral ischaemia or trauma reflect cause rather than effect. ${ }^{19}$ If freeradical mechanisms were to be implicated in the pathogenesis of motor neuron disease an abnormal accumulation of such molecules in cells of the motor system would need to be postulated. It is perhaps somewhat surprising that no evidence of increased free-radical activity was found since several chronic degenerative disorders have been shown to be associated with increased free-radical reaction products. Halliwell and Gutteridge have indeed indicated that degeneration of tissues might of itself lead to an increase in free-radical reaction products. ${ }^{20}$ There does not seem to be any evidence from CSF examination of this occurring in the neuronal degeneration of motor neuron disease.

Evidence of impaired antioxidant activity has, however, been found in the CSF in NCL but it would seem unlikely that the situation pertaining to motor neuron disease is entirely analogous to that in NCL. Anatomically widespread neuronal degeneration occurs in both disorders. In NCL, multi-system degeneration occurs whereas in MND the degenerative process is confined to the motor system and occurs at a microscopic level without disruption to the blood-brain barrier. ${ }^{21}$

It may be that changes in antioxidant activity or increased intraneuronal free-radical accumulation occurs in motor neuron disease but that these abnor- 
malities are not reflected in CSF studies. Further work is necessary to adequately resolve the question as to the possible role of free-radical activity in the pathogenesis of this condition.

The authors thank Dr RJ Prescott of the Medical Statistics Unit of the University of Edinburgh for statistical advice.

\section{References}

1 Gowers WR. A lecture on abiotrophy. Lancet 1902;1:1003-7.

2 McComas AJ, Upton ARM, Sica REP. Motoneurone disease and ageing. Lancet 1973;2:1477-80.

3 Mann DMA, Yates PO. Motor neuron disease-the nature of the pathogenetic mechanism. J Neurol Neurosurg Psychiatry 1974;37:1036-46.

4 Davidson TJ, Hartmann HA. RNA content and volume of motor neurons in amyotrophic lateral sclerosis. J Neuropath Exp Neurol 1981;40:187-92.

5 Bradley WG, Krasin F. A new hypothesis of the etiology of amyotrophic lateral sclerosis. Arch Neurol 1982;39:677-80.

6 Scudiero DA, Brumback RA, Tarone RE, Clatterbuck BE, Robbins JH. Amyotrophic lateral sclerosis and spinal muscular atrophy fibroblasts are not sensitive to killing by a DNA damaging agent. Clin Res 1983;31:292A.

7 Vijayalaxmi, Pentland B, Newton MS, Mitchell JD, Evans HJ. Spontaneous and mutagen induced sister chromatid exchange in motor neuron disease. Mutation Res 1985;150:355-8.

8 Malamud N. Neuromuscular system disease. In: Minkler J, ed. Pathology of the Nervous System Vol I. New York: McGrawHill, 1968:712-25.

9 McHolm GB, Aguilar MJ, Norris FH. Lipofuscin in amyotrophic lateral sclerosis. Arch Neurol 1984;41:1187-8.
10 Gutteridge JMC, Rowley DA, Halliwell B, Westermarck T. Increased non-protein bound iron and decreased protection against superoxide-radical damage in cerebrospinal fluid from patients with neuronal ceroid lipofuscinoses. Lancet 1982:2:459-60.

11 Santavouri P, Westermarck T. Antioxidant therapy in neuronal ceroid lipofuscinoses. Medical Biology 1984;62:152-3.

12 Del Maestro RE. An approach to free radicals in medicine and biology. Acta Physiol Scand 1980;Suppl 492:153-68.

13 Miyata S, Nakamura S, Nagata H, Kameyama $M$. Increased manganese level in spinal cords of amyotrophic lateral sclerosis determined by radiochemical neutron activation analysis. J Neurol Sci 1983;61:283-93.

14 Mitchell JD, East BW, Harris IA, Prescott RJ, Pentland B. Trace elements in the spinal cord and other tissues in motor neuron disease. J Neurol Neurosurg Psychiatry 1986;49:211-5.

15 Recknagel RO, Ghoshal AK. Quantitative estimation of peroxidative degeneration of rat liver microsomal and mitochondrial lipids after carbon tetrachloride poisoning. Exp $\mathrm{Mol}$ Pathol 1966;5:413-26.

16 Fletcher BL, Dillard CJ, Tappel AC. Measurement of fluorescent lipid peroxidation products in biological systems and tissues. Anal Biochem 1973;52:1-9.

17 Wickens DG, Graff TL, Lunec J, Dormandy TL. Free radical mediated aggregation of human gamma-globulin. Agents Actions 1981;11:650-1.

18 Wickens DG, Norden AG, Lunec J, Dormandy TL. Fluorescent changes in human gamma-globulin induced by free radical activity. Biochem Biophys Acta 1983;742:607-16.

19 Halliwell B, Gutteridge JMC. The importance of free radicals and catalytic metal ions in human diseases. Mol Aspects Med 1985;8:89-193.

20 Halliwell B, Gutteridge JMC. Lipid peroxidation, oxygen radicals, cell damage and antioxidant therapy. Lance 1984;2:1369-7.

21 Blundell G, Mitchell JD. The use of intrathecal IgG synthetie rates in diagnosis. In: Peeters $\mathrm{H}$, ed. Protides of the Biologicas Fluids Vol 32. Oxford: Pergamon Press, 1985:187-90. 